Электронная версия доступна на сайте

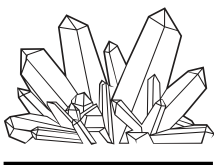

www.fmm.ru/Новые данные о минералах

Минералогический музей

имени А.Е. Ферсмана РАН

Новые данные о минералах, том 55, вып. 1 (2021), 5-13

\title{
Силикатные включения в минералах системы Os-Ir-Ru россыпи Адамсфилд (Западная Тасмания)
}

\author{
А.В. Кутырев ${ }^{1,2}$, В.С. Каменецкий ${ }^{1,2}$, Н.А. Некрылов ${ }^{3}$ \\ ${ }^{1}$ Институт вулканологии и сейсмологии ДВО РАН, Петропавловск-Камчатский, \\ ${ }^{2}$ Институт экспериментальной минералогии РАН \\ anton.v.kutyrev@gmail.com,dima.kamenetsky@utas.edu.au \\ ${ }^{3}$ Минералогический музей им. А.Е. Ферсмана РАН, Москва, nekrilov.n@gmail.com
}

Изучены коллекции зерен самородного осмия из россыпи Адамсфилд (Западная Тасмания). Большинство зерен однородны по составу, средний состав самородного осмия: Os 52.9 мас.\%, $\operatorname{Ir} 41.2$ мас.\% и Ru 6.4 ас.\%. Другие минералы (самородный иридий, изоферроплатина, самородный рутений, сульфиды и арсениды платиноидов) встречаются редко. Вероятный коренной источник зерен - хромититы в офиолитовом ультрамафическом комплексе Адамсфилд. В зернах самородного осмия россыпи Адамсфилд обнаружены полиминеральные включения, сложенные оливином, ортопироксеном, хромшпинелидом, роговой обманкой, низкокальциевыми амфиболами (куммингтонитом или антофиллитом), кварцем, анортитом, слюдами. Форма включений гексагональная, отвечающая отрицательным кристаллам. Включения с трудом поддаются интерпретации по модели, разработанной предшественниками (прямая кристаллизация самородного осмия из бонинитового расплава), и больше соответствуют современным представлениям об образовании хромитовой и платиновой минерализации в офиолитовых гипербазитах в результате реакции гарцбургитов с субдукционными расплавами и флюидами. Ряд особенностей морфологии и состава минералов предполагает крайнюю гетерогенность минералообразующей среды, равно как и значительную роль метаморфических и метасоматических процессов в образовании изученной минеральной ассоциации.

Ключевые слова: МПГ, осмий, включения, метаморфизм, субдукция.

\section{Введение}

Большинство современных моделей образования хромититов офиолитовых гипербазитов предполагают реакцию между расплавом и породой, смешение расплавов или же оба этих процесса (Arai, 1997; González-Jiménez et al., 2014; Rollinson et al., 2018). К числу причин, которые заставили исследователей обратиться к таким моделям, относятся: (1) невозможность объяснить фракционной кристаллизацией огромное относительно оливина количество хромшпинелида, (2) крайне сложная морфология хромититовых тел, не позволяющая объяснить их образование гравитационным накоплением, и (3) присутствие в хромшпинелиде силикатных включений, отличающихся высоким содержанием $\mathrm{SiO}_{2}, \mathrm{Na}, \mathrm{K}, \mathrm{H}_{2} \mathrm{O}$ и ряда других компонентов относительно вмещающей минерализацию ультрамафической породы (как правило, дунита или гарцбургита). Последнее особенно интересно, ведь рядом работ было показано, что аналогичные включения встречаются и в минералах платиновой группы (МПГ) из офиолитовых хромититов (Дмитренко, Мочалов, 1989; Peck et al., 1992). В частности, в россыпных проявлениях Корякии были обнаружены зерна минералов системы Os-Ir-Ru, содержащие включения амфиболов (Дмитренко и Мочалов, 1989; Мочалов, 2001). В этих работах были сделаны выводы о флюидно-метаморфогенном генезисе Os-Ir-Ru-минера- 
лизации. Примерно в то же время вышла статья, посвященная включениям в Os-Ir-Ru-минералах россыпного узла Адамсфилд, Тасмания (Peck et al., 1992). Авторы этой работы описали включения оливина и двух ортопироксенов (низко- и высококальциевого), проинтерпретировав их как результат захвата твердой фазы. В последующем они сделали вывод о прямой кристаллизации МПГ из бонинитового расплава, содержавшего фенокристы оливина и ортопироксена (Peck et al., 1992). Taким образом, выводы двух групп исследователей оказались полностью противоположны. После публикации этих работ в исследовании включений в МПГ офиолитовых гипербазитов случился двадцатилетний перерыв. В литературе можно встретить отдельные упоминания силикатных включений в МПГ офиолитовой ассоциации (Barkov et al., 2005), однако специализированные исследования по этой теме не проводились.

Настоящая работа ставит перед собой следующие задачи: (а) на современном уровне охарактеризовать ассоциацию МПГ россыпи Адамсфилд; (б) исследовать силикатные включения в МПГ и рассмотреть их с точки зрения современных представлений об образовании аналогичных включений в хромшпинелиде офиолитовых гипербазитов.

\section{Россыпь Адамсфилд}

Западная Тасмания - единственный в мире регион, в котором Os, Ir и Ru добывались из россыпей в качестве основного, а не попутного компонента. В период между 1910 и 1950 годом на россыпи Адамсфилд и находящейся в 150 км к северу от нее россыпи Хезлвуд Ривер было суммарно добыто 964 кг Os, Ir и Ru (Twelvetrees, 1914; Reid, 1921; Mertie, 1969). Наиболее вероятным источником для минералов является расположенный поблизости массив офиолитовых гипербазитов Адамсфилд. Сам массив является малоизученным, однако в хромититах одновозрастного и близкого по геологическому строению массива Хезлвуд Ривер были установлены высокие содержания Os, Ir, $\mathrm{Ru}$ и $\mathrm{Pt}$ (до 1.7, 1.8, 2.0 и 0.5 г/т соответственно, Peck and Keays, 1990). С учетом того, что многие зерна МПГ содержат включения хромшпинелида, a Os$\mathrm{Ir}-\mathrm{Ru}$-интерметаллиды являются типичными рудными минералами для хромититов офиолитовых гипербазитов (El Ghorfi et al., 2007; Kiseleva and Zhmodik, 2017; Prichard et al., 2017), можно предположить, что источником для россыпи послужили расположенные в массиве Адамсфилд хромититы.

\section{Методы исследования и материалы}

Материалы, положенные в основу исследования, были получены австралийским геологом
Рэмзи Фордом и с конца 1980-х годов хранились в фондах Университета Тасмании, который любезно предоставил их авторам настоящей статьи. Они представляют собой зерна металлов платиновой группы, выделенные из шлиховых концентратов. Помимо МПГ, в концентратах встречаются единичные зерна самородного золота и силикатов.

Минералы были вмонтированы в эпоксидную смолу, отполированы и изучены в Университете Тасмании на сканирующем электронном микроскопе Hitachi SU-70 с катодом Шотке, укомплектованном энергодисперсионным детектором Oxford IncaEnergy X-Max 80, и в Институте вулканологии и сейсмологии ДВО РАН на электронном микроскопе Tescan VEGA-3, укомплектованном аналогичным детектором.

\section{Минералы платиновой группы}

\section{Россыпный узел Адамсфилд}

Изученная коллекция представлена сотнями зерен, размер которых колеблется от десятых долей до первых миллиметров. Подавляющее большинство из них приходится на Os-Ir-Ru-минералы (рис. 1а-в), и лишь единичные зерна относятся к изоферроплатине (рис. 1г).

Изученные зерна слабо окатаны, у некоторых слабо проявлена кристаллическая огранка, в редких случаях встречаются срастания с хромшпинелидом (рис. 1а, в). Среди зерен изоферроплатины встречены кристаллы кубического габитуса (рис. 1г). Средний состав самородного осмия: Os 52.9 мас.\%, Ir 41.2 мас.\% и Ru 6.4 мас.\%, вариации незначительны (рис. 2, табл. 1).

Включения самородного осмия в изоферроплатине отличаются большим содержанием Os и меньшим Ir и Ru (рис. 2). Другие минералы системы Os-Ir-Ru - самородный иридий и самородный рутений - встречаются значительно реже. Самородный иридий образует включения в самородном осмии, а самородный рутений был встречен исключительно в виде ориентированных ламелей, образующих тонкую сетку в изоферроплатине. Другие минералы представлены лауритом (Ru,Os) $\mathrm{S} 2$, ирарситом IrAsS, холлингуортитом RhAsS, сульфидами родия и неназванным арсенидом родия и палладия. Можно отметить, что в сравнении с другими россыпями, связанными с офиолитами, Адамсфилд обладает исключительно однообразным минеральным составом.

\section{Полиминеральные включения}

Более половины изученных россыпных зерен содержат полиминеральные силикатные включения, что полностью согласуется с результатами предшественников (Peck et al., 1992). С учетом 

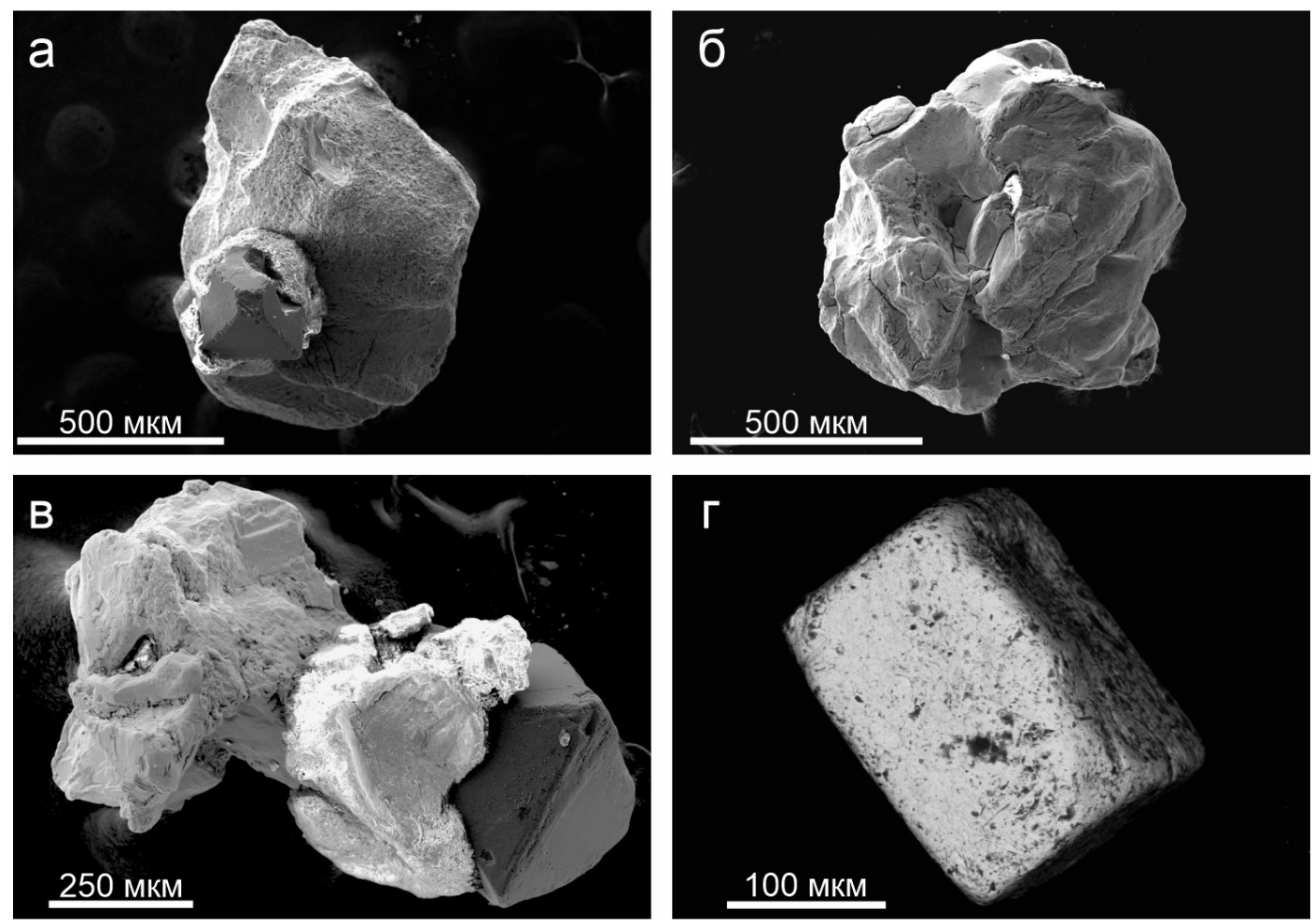

Рис. 1 Зерна самородного осмия (а-в) и изоферроплатины из россыпи Адамсфилд. На рисунках а и в видны октаэдрические кристаллы хромшпинелида. Изображения во вторичных (а-в) и отраженных (г) электронах.

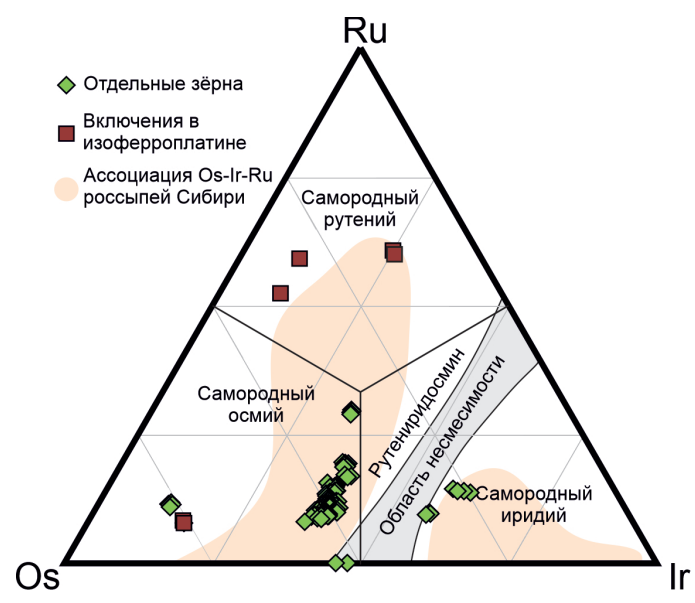

Рис. 2. Тройная диаграмма состава минералов системы Os-Ir-Ru. Для сравнения нанесены поля состава аналогичных минералов из россыпных проявлений Сибири, сопряженных с офиолитовыми гипербазитами (Tolstykh et al., 2002).

того, что многие включения могли остаться невскрытыми при полировке, можно утверждать, что их содержит большинство зерен МПГ. Всего в ходе настоящей работы было изучено более ста отдельных поли- и мономинеральных включений.
В самородном осмии полиминеральные включения в сечении имеют гексагональные очертания, соответствующие симметрии минерала-хозяина, вероятно, отвечая отрицательным кристаллам (рис. 3); в изоферроплатине они имеют форму прямоугольника, что согласуется с кубической сингонией этого минерала. Границы включений, расположенных в одном зерне, параллельны (рис. $3 a, 6)$. Похожие закономерности отмечались ранее при исследовании включений в самородном осмии Красногорского массива (Корякия) и изоферроплатине россыпей Кондёра (Дмитренко, Мочалов, 1989). Во включениях обнаружены амфиболы, по составу отвечающие роговой обманке (рис. 3г, табл. 2, ан. 1-7), ортопироксен (рис. 3д), а также кварц (рис. 3д), альбит, анортит (рис. 3е), слюды, хлорит, хромшпинелид.

При этом амфиболы и кварц слагают подавляющее большинство включений, встречаясь значительно чаще ортопироксена или оливина. Во многих случаях амфиболовое или амфибол-кварцевое включение выполняет только часть гексагональной пустоты в самородном осмии, а другая ее часть выполнена самородным иридием (рис. 3a). Подобные взаимоотношения могут указывать на сингенетичность образования самородного иридия и той фазы, которая, закристаллизовавшись, 

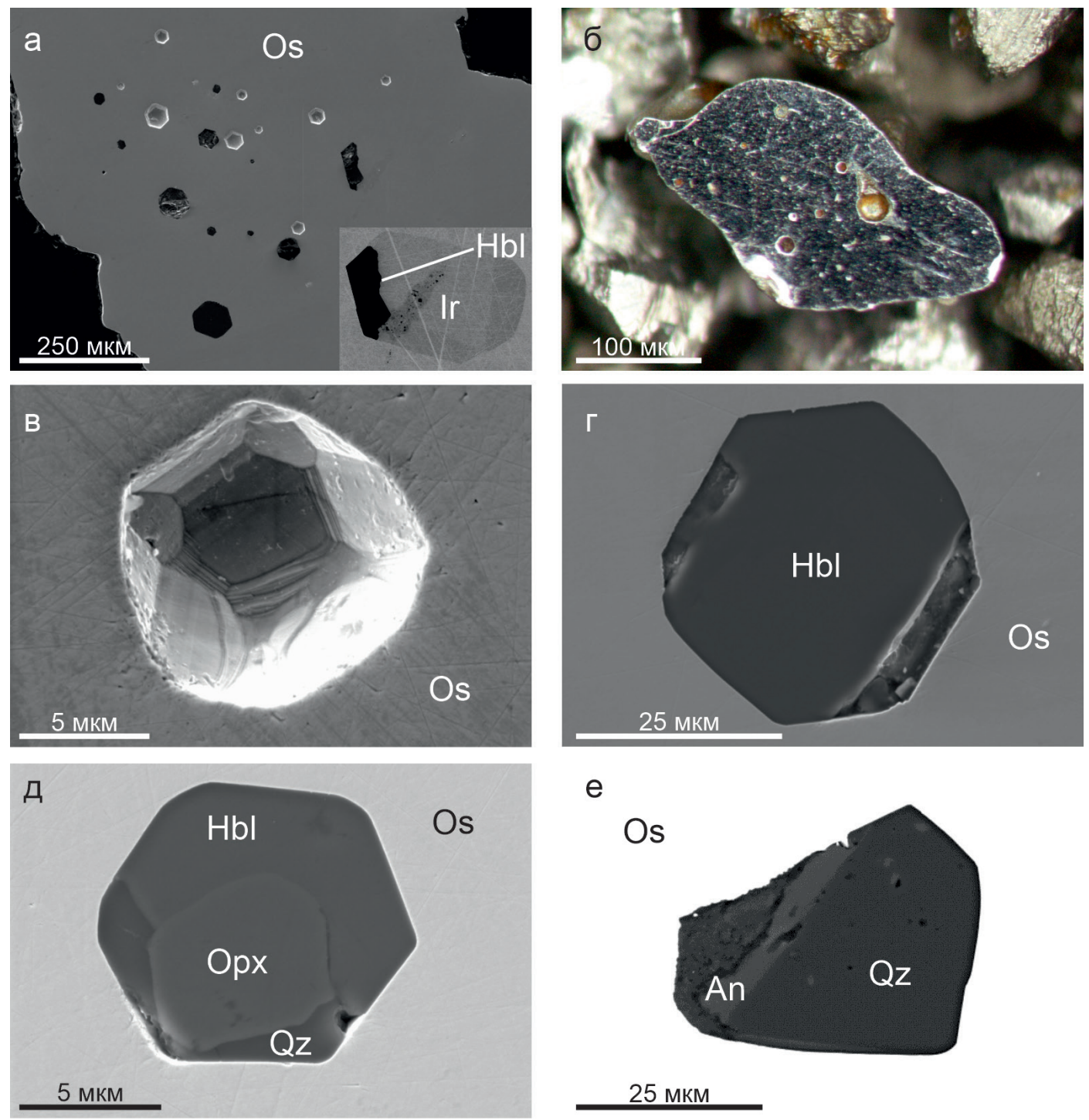

e

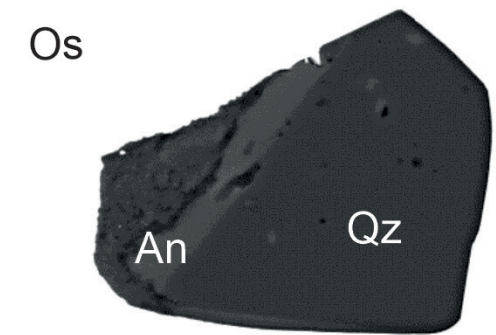

\section{5 МКм}

Рис. 3. Полиминеральные включения в самородном осмии. Обозначения минералов: Os - самородный осмий, Нbl - роговая обманка, Ir - самородный иридий, Opx - ортопироксен, Qz - кварц, An - анортит. Изображения во вторичных (а, в-д) и отраженных (е) электронах, рисунок 6 - фотография. На рисунках а и в показаны отрицательные кристаллы в осмии (заполнявшие их силикаты, вероятно, выкрошились при полировке).

стала амфибол-кварцевым включением. Помимо полиминеральных, амфиболы также образуют и индивидуальные включения (рис. Зг).

Необычное включение представлено на рисунке 4. В нем соседствуют два минерала, состав которых на первый взгляд отвечает ортопироксену. Однако один из них имеет более низкую аналитическую сумму и более темный тон на изображении во вторичных электронах. Поскольку в обоих минералах примесь $\mathrm{Al}$ крайне низкая, простое отношение Si к остальным катионам позволило установить, что темный минерал относится к амфиболам
- куммингтониту или антофиллиту (табл. 2, ан. 8). Нужно подчеркнуть, что достоверно различить по составу ортопироксены и низкокальциевые амфиболы возможно только при низкой примеси $\mathrm{Al}$ (в противном случае трудности возникают из-за неоднозначности распределения $\mathrm{Al}$ между тетраэдрической и октаэдрической позициями). Аналитическая сумма также является не вполне надежным показателем, так как ее дефицит может быть вызван не только присутствием в минерале $\mathrm{OH}$-группы, но и просто низким качеством конкретного анализа. Поэтому можно предположить, 
Таблица 1. Примеры состава минералов системы Os-Ir-Ru

\begin{tabular}{|c|c|c|c|c|c|c|c|c|c|c|c|}
\hline № & $\mathrm{Ru}$ & $\mathrm{Rh}$ & Os & Ir & $\mathrm{Pt}$ & Сумма & $\mathrm{Ru}$ & $\mathrm{Rh}$ & Os & Ir & $\mathrm{Pt}$ \\
\hline \multicolumn{7}{|c|}{ Массовые \% } & \multicolumn{5}{|c|}{ Атомные \% } \\
\hline 1 & 41.06 & 2.17 & 18.66 & 32.64 & 3.71 & 98.24 & 56.88 & 2.95 & 13.73 & 23.77 & 2.66 \\
\hline 2 & 40.97 & 2.21 & 19.02 & 33.74 & 3.53 & 99.47 & 56.27 & 2.98 & 13.88 & 24.36 & 2.51 \\
\hline 3 & 38.95 & 1.21 & 38.81 & 12.94 & 7.67 & 99.58 & 54.45 & 1.66 & 28.82 & 9.51 & 5.55 \\
\hline 4 & 33.46 & 0.99 & 45.57 & 12.66 & 6.25 & 98.93 & 48.82 & 1.42 & 35.33 & 9.71 & 4.72 \\
\hline 5 & 4.44 & 0.95 & 77.35 & 16.28 & - & 99.02 & 8.07 & 1.70 & 74.68 & 15.56 & - \\
\hline 6 & 5.02 & - & 54.09 & 40.45 & - & 99.56 & 9.12 & - & 52.23 & 38.65 & - \\
\hline 7 & 5.75 & - & 54.02 & 41.06 & - & 100.83 & 10.26 & - & 51.21 & 38.52 & - \\
\hline 8 & 5.12 & - & 53.94 & 41.63 & - & 100.69 & 9.20 & - & 51.48 & 39.32 & - \\
\hline 9 & 6.26 & - & 53.89 & 40.27 & - & 100.42 & 11.17 & - & 51.07 & 37.77 & - \\
\hline 10 & 5.28 & - & 53.89 & 40.81 & - & 99.98 & 9.54 & - & 51.71 & 38.75 & - \\
\hline 11 & 6.31 & - & 53.75 & 40.20 & - & 100.26 & 11.27 & - & 50.99 & 37.74 & - \\
\hline 12 & 5.76 & - & 53.65 & 40.93 & - & 100.34 & 10.33 & - & 51.10 & 38.58 & - \\
\hline 13 & 5.27 & - & 53.65 & 41.58 & - & 100.50 & 9.47 & - & 51.23 & 39.30 & - \\
\hline 14 & 6.39 & - & 53.61 & 40.20 & - & 100.20 & 11.41 & - & 50.85 & 37.74 & - \\
\hline 15 & 5.90 & - & 53.59 & 41.34 & - & 100.83 & 10.52 & - & 50.74 & 38.74 & - \\
\hline 16 & 6.50 & - & 53.52 & 40.75 & - & 100.77 & 11.53 & - & 50.45 & 38.02 & - \\
\hline 17 & 11.33 & - & 47.58 & 41.04 & - & 99.95 & 19.47 & - & 43.44 & 37.08 & - \\
\hline 18 & 9.50 & - & 47.53 & 42.89 & - & 99.92 & 16.58 & - & 44.07 & 39.35 & - \\
\hline 19 & 10.98 & - & 47.35 & 41.33 & - & 99.66 & 18.97 & - & 43.47 & 37.55 & - \\
\hline 20 & 10.63 & - & 47.25 & 41.08 & - & 98.96 & 18.54 & - & 43.79 & 37.67 & - \\
\hline 21 & 11.12 & - & 47.19 & 41.41 & - & 99.72 & 19.18 & - & 43.25 & 37.56 & - \\
\hline 22 & 5.11 & - & 35.50 & 58.48 & - & 99.09 & 9.34 & - & 34.47 & 56.19 & - \\
\hline 23 & 5.33 & - & 34.52 & 58.50 & - & 98.35 & 9.79 & - & 33.70 & 56.51 & - \\
\hline 24 & 5.20 & - & 34.45 & 58.81 & - & 98.46 & 9.55 & - & 33.63 & 56.82 & - \\
\hline
\end{tabular}

Примечание. Значения ниже пределов обнаружения отмечены знаком «-». Анализы 1-4 - самородный рутений (включения в изоферроплатине), 5 - самородный осмий (включение в изоферроплатине), 6-21 - самородный осмий (отдельные зерна), 22-23 - самородный иридий (включения в самородном осмии). Самородный рутений образует тесные срастания с изоферроплатиной, поэтому примесь Pt в нем может объясняться влиянием матрицы.

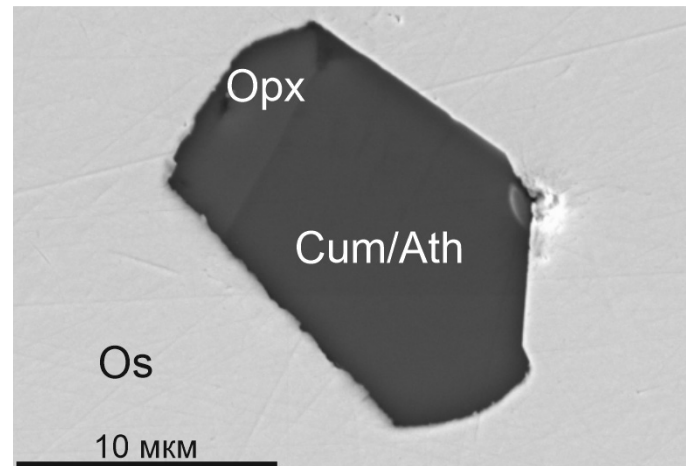

Рис. 4. Включение ортопироксена (Орх) и куммингтонита/антофиллита (Cum/Ath) в самородном осмии (Os). Изображение во вторичных электронах.

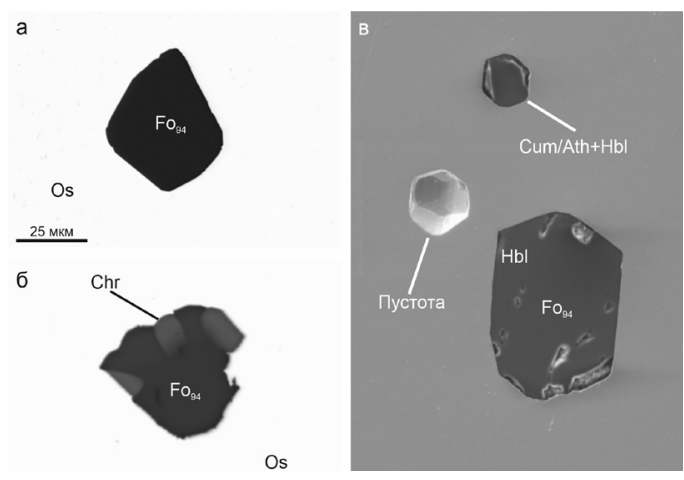

Рис. 5. Включения оливина (Fo), хромшпинелида (Chr), роговой обманки (Hbl), куммингтонита/антофиллита (Cum/Ath) в самородном осмии (Os). Изображения в отраженных $(\mathrm{a}, 6)$ и вторичных (в) электронах. 
что и в других случаях минералы, состав которых отвечает ортопироксену, могут оказаться куммингтонитом или антофиллитом.

Оливин, описанный предшественниками как один из преобладающих минералов (Peck et al., 1992), образует отдельные включения двух типов. Первый тип обладает очертаниями, в которых часто можно предположить следы собственных граней оливина (рис. 5a), либо более сложной формой (рис. 5б). Второй тип - включения оливина, границы которых ориентированы параллельно включениям других минералов. На рисунке 5в представлены закономерно ориентированные оливин-роговообманковое и антофиллит/куммингтонит-роговообманковое включения и пустота, которая ранее, вероятно, была выполнена каким-то силикатом, выкрошившимся в ходе полировки.

Два случая требуют отдельного рассмотрения. В первом из них в зерне самородного осмия наблюдаются два включения (рис. 6а). Одно из них - мономинеральное - сложено высокомагнезиальным оливином $\left(\mathrm{Fo}_{91}\right)$ и роговой обманкой. Второе представляет собой обычное для Адамсфилда включение амфибол-кварцевого состава.

Второй случай можно рассматривать как усложненный вариант первого. Здесь оливин сосуществует в одном включении с роговой обманкой и хлоритом, кварц, как и следует ожидать, отсутствует (рис. 6б). Примечательным является присутствие во включении мелкого зерна хромшпинелида, которое прорастает в амфибол.

Сравнение с полиминеральными включениями в хромшпинелиде из хромититов офиолитовых гипербазитов

Исследования включений в хромшпинелиде офиолитовых гипербазитов сыграли решающую роль в появлении современных представлений о генезисе подиформных хромититов. Присутствие водосодержащих силикатов в таких включениях было показано в ранних работах (Johan and Le Bel, 1978; Johan et al., 1983; Дмитренко и Мочалов, 1989) и в дальнейшем неоднократно подтверждено (Melcher et al., 1997; Rollinson et al., 2018; Rospabé et al., 2021), а высокое содержание воды в расплавах, из которых могли образоваться хромититы, уже стало общим местом в современной литературе. Кроме того, ряд исследователей разработали модели, предполагающие участие гидротермальных и метаморфических процессов вместо или наряду с магматическими в образовании хромититов (Johan et al., 1983; Дмитренко, Мочалов, 1989; Matveev and Ballhaus, 2002; Borisova et al., 2012).

Можно перечислить следующие минералы, наиболее часто упоминаемые в работах по включениям в хромшпинелиде офиолитовых гиперба-
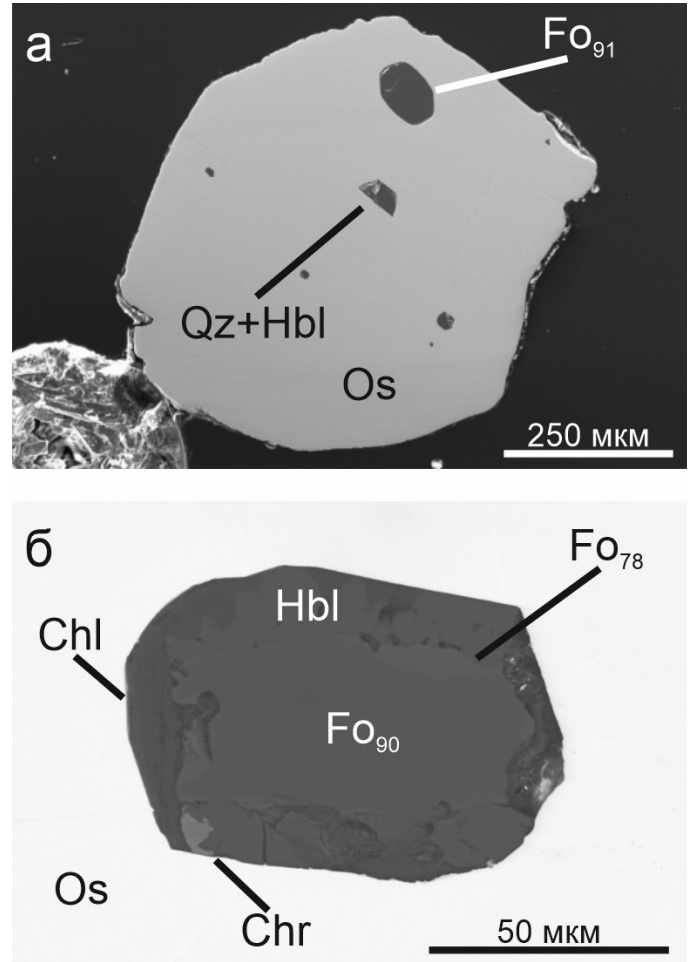

Рис. 6. Редкие случаи совместного нахождения оливина и других минералов: а - соседствующие включения форстерита (Fo), роговой обманки $(\mathrm{Hbl})$ и кварца $(\mathrm{Qz})$; б - включение оливина, роговой обманки, хлорита (Chl) и хромшпинелида (Chr). Изображения во вторичных (a) и отраженных (б) электронах.

зитов (в алфавитном порядке): альбит, амфиболы (преимущественно близкие паргаситу или роговой обманке), клинопироксен, оливин, ортопироксен, аспидолит (Melcher et al., 1997; Borisova et al., 2012; Akmaz et al., 2014; Xiong et al., 2015, 2017; Rospabé et al., 2021). Присутствие амфиболов в качестве преобладающих минералов наряду с второстепенной ролью оливина является общим для включений в хромшпинелиде и МПГ. Общей является и форма включений, которые образуют отрицательные кристаллы как в МПГ, так и в хромшпинелиде (Дмитренко, Мочалов, 1989). Наиболее существенное различие в их минеральном составе - присутствие во включениях в МПГ кварца, который для них является одним из наиболее распространенных минералов.

Близкая ситуация была отмечена при изучении включений в хромшпинелиде и изоферроплатине коренных хромититов Матыскенского концентрически-зонального массива (Kutyrev et al., 2020). Несмотря на то что этот массив относится к другому формационному типу, параллели между ним и исследуемым объектом столь очевидны, что о них нельзя не упомянуть. В протолочках хроми- 
Таблица 2. Примеры состава амфиболов из полиминеральных включений в самородном осмии россыпи Адамсфилд

\begin{tabular}{|c|c|c|c|c|c|c|c|c|c|c|c|c|}
\hline № & $\mathrm{Na}_{2} \mathrm{O}$ & $\mathrm{MgO}$ & $\mathrm{Al}_{2} \mathrm{O}_{3}$ & $\mathrm{SiO}_{2}$ & $\mathrm{~K}_{2} \mathrm{O}$ & $\mathrm{CaO}$ & $\mathrm{TiO}_{2}$ & $\mathrm{Cr}_{2} \mathrm{O}_{3}$ & $\mathrm{MnO}$ & $\mathrm{FeO}$ & Сумма & \\
\hline 1 & 0.70 & 19.35 & 13.55 & 48.78 & - & 11.08 & - & - & 0.17 & 2.50 & 96.13 & \\
\hline 2 & 0.57 & 18.75 & 10.97 & 49.90 & - & 10.84 & 0.16 & 0.33 & - & 4.33 & 95.85 & \\
\hline 3 & 0.75 & 19.82 & 12.51 & 49.33 & - & 11.91 & - & 0.14 & - & 1.69 & 96.15 & \\
\hline 4 & 0.75 & 19.70 & 12.61 & 48.34 & - & 11.90 & - & 0.58 & - & 1.51 & 95.39 & \\
\hline 5 & 0.70 & 17.06 & 6.88 & 50.89 & - & 12.28 & 0.41 & - & - & 7.82 & 96.04 & \\
\hline 6 & 0.39 & 20.92 & 8.29 & 51.45 & - & 13.23 & - & - & - & 1.94 & 96.22 & \\
\hline 7 & 0.68 & 13.62 & 11.03 & 47.09 & 0.12 & 12.22 & 0.17 & - & - & 11.30 & 96.23 & \\
\hline 8 & 0.00 & 24.16 & 0.07 & 56.62 & - & 0.69 & - & - & - & 14.22 & 95.07 & \\
\hline \multicolumn{13}{|c|}{ Формульные коэффициенты, рассчитанные на сумму катионов, кроме $\mathrm{Na}$ и K, $\Sigma$ = 15} \\
\hline № & $\mathrm{Si}$ & $\mathrm{Al}_{\text {tet }}$ & $\mathrm{Al}_{\text {oct }}$ & $\mathrm{Fe}^{3+}$ & $\mathrm{Cr}$ & $\mathrm{Ti}$ & $\mathrm{Fe}^{2+}$ & $\mathrm{Mn}$ & $\mathrm{Mg}$ & $\mathrm{Ca}$ & $\mathrm{Na}$ & $\mathrm{K}$ \\
\hline 1 & 6.79 & 1.21 & 1.02 & - & - & - & 0.29 & 0.02 & 4.02 & 1.65 & 0.19 & - \\
\hline 2 & 7.02 & 0.98 & 0.83 & - & 0.04 & 0.02 & 0.51 & - & 3.93 & 1.63 & 0.16 & - \\
\hline 3 & 6.86 & 1.14 & 0.91 & 0.18 & 0.02 & - & 0.18 & - & 4.11 & 1.77 & 0.20 & - \\
\hline 4 & 6.77 & 1.23 & 0.86 & 0.08 & 0.06 & - & 0.08 & - & 4.12 & 1.79 & 0.20 & - \\
\hline 5 & 7.30 & 0.70 & 0.46 & - & - & 0.04 & 0.94 & - & 3.65 & 1.89 & 0.19 & - \\
\hline 6 & 7.13 & 0.87 & 0.49 & - & - & - & - & - & 4.32 & 1.96 & 0.10 & - \\
\hline 7 & 6.85 & 1.15 & 0.75 & 1.23 & - & 0.02 & 1.23 & - & 2.96 & 1.91 & 0.19 & 0.04 \\
\hline 8 & 8.04 & - & 0.05 & - & - & - & 1.69 & - & 5.11 & 0.10 & - & - \\
\hline
\end{tabular}

Примечание. Значения ниже пределов обнаружения отмечены знаком «-». Анализы 1-7 - магнезиальная роговая обманка, 8 - куммингтонит или антофиллит.

титов Матыскенского массива были обнаружены зерна изоферроплатины, содержащие многочисленные полиминеральные включения. Последние, в отличие от включений в хромшпинелиде, часто содержат альбит, калиево-натриевый полевой шпат, мусковит и в единичном случае кварц. Таким образом, можно предположить, что более продвинутый (т.е. богатый $\mathrm{SiO}_{2}$ ) состав включений в платиноидах в сравнении с включениями в хромшпинелиде является не уникальной особенностью россыпи Адамсфилд, а закономерностью, распространяющейся на гипербазиты различных формационных типов. Это также подтверждается работами по МПГ щелочно-ультраосновных массивов, в которых также были встречены включения продвинутого состава (Дмитренко, Мочалов, 1989).

\section{Генетические следствия: ортомагматическая ин- терпретация}

Полученные результаты не укладываются в рамки модели, предложенной предшественниками (захват ранних фенокристов оливина и ортопироксена в ходе прямой кристаллизации МПГ из бонинитового расплава, Peck et al., 1992). В частности, эта модель не учитывала амфибол-кварцевые (рис. 3д) и кварц-анортитовые (рис. 3е) включе- ния, впервые описанные для Адамсфилда в настоящей работе. Более того, морфология включений была интерпретирована ими как результат захвата идиоморфных кристаллов (Peck et al., 1992), что не согласуется с новыми данными. Целесообразно попробовать рассмотреть новые данные с позиции современных моделей, предполагающих образование хромититов (а следовательно, и платиновой минерализации) в резулмьтате реакции расплав-мантия (Arai, 1997; Melcher et al., 1997). Кратко такие модели можно свести к следующему (некоторые детали опущены):

а). Примитивный расплав, проходя через гарцбургитовое тело, вызывает инконгруэнтное плавление ортопироксена, обогащаясь при этом Si и Cr. Получается богатый $\mathrm{Mg}$, Si и $\mathrm{Cr}$ бонинитовый расплав и оливин двух генераций - образовавшийся за счет ортопироксена и присутствовавший в породе изначально (Kelemen, 1990; Arai and Yurimoto, 1994).

б). Следующая порция примитивного расплава смешивается бонинитовым. В результате этого может появиться расплав, значительно пересыщенный по Cr, и начаться ликвидусная кристаллизация хромшпинелида (Arai and Yurimoto, 1994).

При этом совместное нахождение МПГ и хромшпинелида объясняется моделью, разрабо- 
танной для недосыщенных сульфидной серой систем: при кристаллизации хромшпинелида, отношение $\mathrm{Fe}^{3+} / \mathrm{Fe}^{2+}$ в котором значительно выше, чем в расплаве, происходит уменьшение $\mathrm{fO}_{2}$ в небольшой области вокруг растущего зерна (Mungall, 2002; Finnigan et al., 2008). Поскольку растворимость элементов платиновой группы (ЭПГ) в силикатных расплавах очень сильно зависит от $\mathrm{fO}_{2}$ (Borisov and Palme, 2000), даже небольшой сдвиг этого параметра в меньшую сторону может вызвать пересыщение расплава платиноидами (кроме Pd) и кристаллизацию МПГ.

На первый взгляд такая модель позволяет объяснить присутствие необычных включений в МПГ. Расчет среднего состава включения кварц-куммингтонит-роговообманкового состава (рис. 3д) на основании измерения площади сечений и состава минералов действительно дал значения, близкие к бонинитовому расплаву (в мас.\%: $\mathrm{SiO}_{2}$ 57.7, $\mathrm{Mg}$ 7.2, $\mathrm{Al}_{2} \mathrm{O}_{3}$ 8.1, FeO 8.3, $\mathrm{CaO} 5.8, \mathrm{Na}_{2} \mathrm{O}$ 0.3). Такой продвинутый расплав, образовавшийся при растворении ортопироксена, мог быть захвачен как чистом виде, приводя к образованию богатых $\mathrm{SiO}_{2}$ включений (рис. 3д), так и совместно с оливином, что должно было привести к смещению состава включения в менее продвинутую область и исчезновению кварца. Последний случай можно увязать с ситуацией, представленной на рисунке 66.

\section{Генетические следствия: слабые места ортомаг- матических моделей}

Ортомагматические модели оставляют без ответа ряд вопросов. Первый из них можно сформулировать следующим образом: как в одном зерне оказались захвачены включения высокомагнезиального оливина и кварца? Если предположить, что кварц-амфиболовые включения являются расплавными, а оливин - ранним захваченным минералом, то единственное возможное объяснение сводится к крайней (на уровне микрометров) гетерогенности минералообразующей среды либо к многостадийности процесса. Скорее всего, имели место оба фактора.

Вторую трудность вызывают два типа оливиновых включений. По крайней мере часть включений ориентирована параллельно включениям других минералов (рис. 5в) - вероятно, оливин тоже может образовывать отрицательные кристаллы в осмии, то есть кристаллизоваться in situ. Очевидно, такие включения не могут быть расплавными, равно как и не могут представлять собой результат захвата раннего, ликвидусного оливина - в противном случае они были бы идиоморфными.

Логично распространить этот вывод и на по- лиминеральные включения, ведь преобладающие в полиминеральных включениях роговая обманка (рис. 3г) и ортопироксен (рис. 4в) тоже могут образовывать и мономинеральные включения, которые трудно объяснить кристаллизацией какого-либо гомогенного расплава в закрытой системе.

Таким образом, ни интерпретация Peck et al., 1992, предположивших захват растущим осмием ранних минералов бонинитового расплава, ни преобладающие в литературе объяснения включений в хромшпинелиде захватом расплава (Rollinson et al., 2018) не могут удовлетворительно объяснить имеющийся набор минералов. Альтернативные объяснения должны включать субсолидусные процессы, в первую очередь перекристаллизацию и образование минералов при взаимодействии мантия-флюид. Таким образом, среди двух известных моделей образования полиминеральных включений в МПГ офиолитовых гипербазитов более близкой к истине представляется флюидно-метаморфическая модель (Дмитренко, Мочалов, 1989). Она, однако, требует существенной конкретизации.

\section{Заключение}

1. В зернах самородного осмия и изоферроплатины россыпи Адамсфилд обнаружены ранее не установленные минералы, в том числе роговая обманка, кварц, анортит, слюды, низкокальциевые амфиболы.

2. Морфология включений, отвечающих отрицательным кристаллам, а также их состав делают невозможными простые сценарии их образования, такие как прямая кристаллизация МПГ из какого-либо расплава и захват ликвидусных минералов.

3. Среда, в которой происходило образование МПГ, отличалась крайней гетерогенностью, а сам процесс, вероятно, был многостадийным.

4. Ряд особенностей, такие как присутствие в самородном осмии отрицательных кристаллов, выполненных высокомагнезиальным оливином или ортопироксеном, могут быть объяснены только участием субсолидусных процессов в формировании минерализации.

\section{Благодарности}

Материалы, положенные в основу этой работы, попали в наше распоряжение благодаря содействию профессора Дэвида Грина, которому мы искренне благодарны. Большую помощь в подготовке и анализе образцов оказали Майя Каменецкая и Карстен Геманн.

Работа выполнена при финансовой поддержке гранта РНФ №21-17-00122. 
Дмитренко Г.Г., Мочалов А.Г. О происхождении включений водосодержащих силикатов в платиноидных минералах и хромшпинелидах ультрамафитов // Докл. AH CCCP. 1989. Т. 307. № 5. С. 1207-1211.

Мочалов А.Г. «Шлиховая платина» россыпей Дальнего Востока России. Диссертация на соискание уч. степени д-ра геол.-мин. наук. М.: ИГЕМ, 2001. 296 с.

Akmaz R.M., Uysal I., Saka S. Compositional variations of chromite and solid inclusions in ophiolitic chromitites from the southeastern Turkey: Implications for chromitite genesis // Ore Geology Reviews. 2014. V. 58. P. 208-224.

Arai S. Origin of podiform chromitites // Journal of Asian Earth Sciences. 1997. V. 15. № 2/3. P. 303-310.

Arai S., Yurimoto H. Podiform chromitites of the TariMisaka ultramafic complex, Southwestern Japan, as mantlemelt interaction products // Economic Geology. 1994. V. 89. P. 1279-1288.

Barkov A.Y., Fleet M.E., Nixon G.T., Levson V.M. Platinum-group minerals from five placer deposits in British Columbia, Canada // Canadian Mineralogist. 2005. V. 43. № 5. P. 1687-1710.

Borisov A., Palme H. Solubilities of noble metals in Fecontaining silicate melts as derived from experiments in $\mathrm{Fe}$ free systems // American Mineralogist. 2000. V. 85. № 11/12. P. 1665-1673.

Borisova A.Y., Ceuleneer G., Kamenetsky V.S., Arai S., Béjina F., Abily B., Bindeman I.N., Polvé M., de Parseval P., Aigouy T., Pokrovski G.S. A new view on the petrogenesis of the Oman ophiolite chromitites from microanalyses of chromite-hosted inclusions // Journal of Petrology. 2012. V. 53. № 12. P. 2411-2440.

El Ghorfi M., Melcher F., Oberthür T., Boukhari A.E., Maacha L., Maddi A., Mhaili M. Platinum group minerals in podiform chromitites of the Bou Azzer ophiolite, Anti Atlas, Central Morocco // Mineralogy and Petrology. 2007. V. 92. № $1 / 2$. P. 59-80.

Finnigan C.F., Brennan J.M., Mungall J.E., McDonough W.F. Experiments and models bearing on the role of chromite as a collector of platinum group minerals by local reduction // Journal of Petrology. 2008. V. 49. № 9. P. 1647-1665.

González-Jiménez J.M., Griffin W.L., Proenza J.A., Gervilla F., O'Reilly S.Y., Akbulut M., Pearson N.J., Arai S. Chromitites in ophiolites: How, where, when, why? Part II. The crystallization of chromitites // Lithos. 2014. V. 189. P. $140-158$.

Johan Z., Dunlop H., Le Bel L., Robert J.L., Volfinger $M$. Origin of chromite deposits in ophiolitic complexes: Evidence for a volatile- and sodium-rich reducing fluid phase // Fortschritte der Mineralogie. 1983. V. 61. P. 105-107.

Johan Z., Le Bel L. Sur la genese des couches et podes de chromite dans les complexes ophiolitique // Serv. Geol. Nat. BRGM. 1978. P. 96-99.

Kelemen P.B. Reaction between ultramafic rock and fractionating basaltic magma I. Phase relations, the origin of calc-alkaline magma series, and the formation of discordant Dunite // Journal of Petrology. 1990. V. 31. P. 51-98.

Kiseleva O., Zhmodik S. PGE mineralization and melt composition of chromitites in Proterozoic ophiolite complexes of Eastern Sayan, Southern Siberia // Geoscience Frontiers. 2017. V. 8. № 4. P. 721-731.
Kutyrev A.V., Kamenetsky V.S., Sidorov E.G., Abersteiner A., Chubarov V.M. Silicate inclusions in isoferroplatinum: Constraints on the origin of platinum mineralization in podiform chromitites // Ore Geology Reviews. 2020. V. 119. 103367.

Matveev S., Ballhaus C. Role of water in the origin of podiform chromitite deposits // Earth and Planetary Science Letters. 2002. V. 203. № 1. P. 235-243.

Melcher F., Grum W., Simon G., Thalhammer T.V., Stumpfl E.F. Petrogenesis of the ophiolitic giant chromite deposits of Kempirsai, Kazakhstan: A study of solid and fluid inclusions in chromite // Journal of Petrology. 1997. V. 38. № 10. P. 1419-1458.

Mertie J.B., Jr. Economic geology of the platinum group metals. United States Geological Survey, Professional Paper / U.S. Geolo: USGS, 1969. United States Geological Survey, Professional Paper. - $630 \mathrm{c}$.

Mungall J. A model for co-precipitation of platinumgroup minerals with chromite from silicate melts // International Platinum Symposium, 9th, 21-25 July, 2002, Billings, Montana, Duke University, Abstracts with Program. 2002. P. 321-324.

Peck C., Keays R.R. Insights into the behavior of precious metals in primitive, S-undersaturated magmas: Evidence from the Heazlewood River Complex, Tasmania //. 1990. V. 85. P. 765-793.

Peck D.C., Keays R.R., Ford R.J. Direct crystallization of refractory platinum-group element alloys from boninitic magmas: Evidence from Western Tasmania // Australian Journal of Earth Sciences. 1992. V. 39. № 3. P. 373-387.

Reid A.M. Osmiridium in Tasmania // Geological Survey of Tasmania, Bulletin. 1921. V. 32.123 p.

Prichard H.M., Barnes S.J., Dale C.W., Godel B., Fisher P.C., Nowell G.M. Paragenesis of multiple platinum-group mineral populations in Shetland ophiolite chromitite: 3D X-ray tomography and in situ Os isotopes // Geochimica et Cosmochimica Acta. 2017. V. 216. P. 314-334.

Rollinson H., Mameri L., Barry T. Polymineralic inclusions in mantle chromitites from the Oman ophiolite indicate a highly magnesian parental melt // Lithos. 2018. V. 310/311. P. 381-391.

Rospabé M., Ceuleneer G., Benoit M., Abily B., Pinet P. Origin of the dunitic mantle-crust transition zone in the Oman ophiolite: The interplay between percolating magmas and high-temperature hydrous fluids // Geology. 2017. V. 45. № 5. P. 471-474.

Tolstykh N., Krivenko A., Sidorov E., Laajoki K., Podlipsky $M$. Ore mineralogy of PGM placers in Siberia and the Russian Far East // Ore Geology Reviews. 2002. V. 20. № 1. P. 1-25.

Twelvetrees W.H. The Bald Hill osmiridium field // Geological Survey of Tasmania Bulletin. 1914. V. 17. 14 p.

Xiong F., Yang J., Robinson P.T., Gao J., Chen Y., Lai S. Petrology and geochemistry of peridotites and podiform chromitite in the Xigaze ophiolite, Tibet: Implications for a suprasubduction zone origin // Journal of Asian Earth Sciences. 2017. V. 146. № December 2016. P. 56-75.

Xiong F., Yang J., Robinson P. T., Xu X., Liu Z., Li Y., Li J., Chen $S$. Origin of podiform chromitite, a new model based on the Luobusa ophiolite, Tibet // Gondwana Research. 2015. V. 27(2). P. 525-542. 